\title{
Diabetic Foot Infection Impostors
}

\author{
${ }^{1}$ Subhash K Wangnoo, ${ }^{2}$ Radhika Jindal, ${ }^{3}$ Mohammad A Siddiqui
}

\begin{abstract}
Diabetic foot complications continue to be the main reason for diabetes-related hospitalization and lower extremity amputations. Most can be cured if managed properly. But improper diagnostic and therapeutic approaches result in many patients needlessly undergoing amputations. There are many other conditions "imposing" as a diabetic foot, which may mislead the diagnosis and management. One should be aware of these conditions and keep a watchful eye for them as well in a diabetic patient. Every ulcer in a diabetic need not be a diabetic foot ulcer. Some of these diabetic foot infection imposters are discussed herewith and these include pyoderma gangrenosum, squamous cell carcinoma in a chronic ulcer, venous ulcer, bullosis diabeticorum, necrobiosis lipoidica diabeticorum, malignant melanoma, thromboangiitis obliterans (TAO), superficial thrombophlebitis, erythema nodosum, and granuloma annulare.
\end{abstract}

Keywords: Cellulitis, Diabetic foot, Foot ulcer.

How to cite this article: Wangnoo SK, Jindal R, Siddiqui MA. Diabetic Foot Infection Impostors. J Foot Ankle Surg (AsiaPacific) 2016;3(2):88-91.

\section{Source of support: Nil}

\section{Conflict of interest: None}

\section{INTRODUCTION}

Diabetic foot complications continue to be the main reason for diabetes-related hospitalization and lower extremity amputations. Most can be cured if managed properly. But improper diagnostic and therapeutic approaches result in many patients needlessly undergoing amputations. The lifetime risk for the development of a foot ulcer in a diabetic patient is about $25 \%$. The annual incidence of ulceration is about $2 \%$; it increases to $7 \%$ in the presence of diabetic neuropathy; and it is almost $50 \%$ with a previous history of ulceration. ${ }^{1}$

Diabetic foot infections typically occur as one of these forms: Cellulitis, deep-skin and soft tissue infections, acute osteomyelitis, and chronic osteomyelitis. Cellulitis occurs as a tender, erythematous, nonraised skin lesion,

\footnotetext{
${ }^{1,3}$ Senior Consultant, ${ }^{2}$ Consultant

${ }^{1-3}$ Department of Apollo Centre for Obesity, Diabetes and Endocrinology, Indraprastha Apollo Hospitals, New Delhi India
}

Corresponding Author: Subhash K Wangnoo, Senior Consultant, Department of Apollo Centre for Obesity, Diabetes and Endocrinology, Indraprastha Apollo Hospitals, New Delhi India, Phone: +911129874168, e-mail: subhashwang@hotmail. com sometimes with lymphangitis. Bullae may occur, and are typical of Staphylococcus aureus infection, but occasionally occur with group I streptococci as well. There is no ulcer or wound exudate present. In deep-skin and soft tissue infections, there is an ulcer, with or without a wound discharge, which may be foul smelling (Fig. 1A). The patient may be acutely ill, with painful induration of the soft tissues in the extremity. In mixed infections that may involve anaerobes, crepitation may be noted over the afflicted area. Gangrene may also be present. Acute osteomyelitis is usually painful at the site of the involved bone, unless the patient has peripheral neuropathy. Usually, fever and regional lymphadenopathy are absent. In chronic osteomyelitis, pain may or may not be present, depending on the degree of peripheral neuropathy. Deep, penetrating ulcers (Fig. 1B) and deep sinus tracts (diagnostic of chronic osteomyelitis) are usually found. Wound discharge is present and is commonly foul smelling. There is absence of lymphangitis.

The classic diabetic foot must be distinguished from various other problems that tend to occur in persons with diabetes. "Impostor" in the Oxford Dictionary means a person who pretends to be someone else in order to deceive others. There are many other conditions "imposing" as a diabetic foot, which may mislead the diagnosis and management. One should be aware of these conditions and keep a watchful eye for them as well in a diabetic patient. Every ulcer in a diabetic need not be a diabetic foot ulcer. Some of these diabetic foot infection impostors are discussed herewith and these include pyoderma gangrenosum, squamous cell carcinoma in a chronic ulcer, venous ulcer, bullosis diabeticorum, necrobiosis lipoidica diabeticorum, malignant melanoma, thromboangiitis obliterans (TAO), superficial thrombophlebitis, erythema nodosum, and granuloma annulare.

\section{PYODERMA GANGRENOSUM}

Pyoderma gangrenosum is an uncommon, ulcerative cutaneous condition (Fig. 1C). Although the etiology is poorly understood, dysregulation of the immune system is believed to be involved. The initial lesion is usually a bite reaction, with a small, red papule or pustule changing into a larger, ulcerative lesion. It is later characterized by a deep ulceration with a violaceous border that overhangs the ulcer bed. Pain is the predominant historical complaint. It is associated with involvement of other organ 
systems in at least $50 \%$ of patients who are affected. Other organs systems that may be involved include the heart, the central nervous system, the gastrointestinal tract, the eyes, the liver, the spleen, the bones, and the lymph nodes. About $25 \%$ patients with pyoderma gangrenosum have diabetes. The diagnosis is made by excluding other causes of similar-appearing cutaneous ulcerations, including infection, malignancy, vasculitis, collagen vascular diseases, diabetes, and trauma. Treatment involves the use of anti-inflammatory agents, antibiotics, corticosteroids, immunosuppressive agents, and biologic agents. The prognosis is generally good; however, the disease can recur and residual scarring is common. ${ }^{2-4}$

\section{SQUAMOUS CELL CARCINOMA IN A CHRONIC ULCER (MARJOLIN ULCER)}

Chronic ulcers are common in patients with diabetic foot, mostly because they are usually painless due to the coexisting peripheral neuropathy. One should always look out for any red flag signs suggestive of a carcinoma in a chronic foot ulcer.

The mechanism by which chronic ulcers transform into malignancies is not well known. There are various postulations. ${ }^{5-7}$ One such theory suggests that toxins released from the damaged ulcer tissue can act as carcinogens and subsequently lead to tumor development. It has also been postulated that with chronic irritation and repeated damage of the ulcer, there is repeated attempt at repair. This cycle of damage, irritation, and repair can lead to malignant transformation. Another proposed theory of malignant transformation is the initiation and promotion phase theory. In the initiation phase, normal cells are converted to dormant malignant cells. In the subsequent promotion phase, the dormant cells are then stimulated to change into a tumor by infection, which can act as a cocarcinogen.

Ulcer features that are suggestive of malignant transformation include a chronic ulcer of greater than 3 months duration, excessive granulation tissue extending beyond the margins, everted wound edges, and translucent or shiny granulation tissue affecting ulcer margins (Fig. 1D). Other features that may raise suspicion that the ulcer is malignant, include recurrent breakdown of ulcers after healing, static nonhealing ulcers after appropriate treatment, and ulcers that increase in size or pain despite appropriate therapy. Absence of concomitant vascular or neurological deficits also raises the suspicion of an etiology other than diabetic foot. Several treatment modalities are used in the management of ulcer lesions with squamous cell carcinoma, including surgical excision and radiation therapy. $5,8,9$
Marjolin's ulcers are most commonly found in the lower extremity, especially the plantar foot. One should always consider malignancy arising in association with chronic osteomyelitis in the diabetic foot.

\section{VENOUS ULCER}

The term chronic venous insufficiency describes a condition that affects the venous system of the lower extremities with venous hypertension causing various pathologies including pain, swelling, edema, skin changes, and ulcerations. Venous ulcer, also known as stasis ulcer, is the most common etiology of lower extremity ulceration. ${ }^{10}$ Nonhealing ulcers are often noted around the medial malleolus, where venous pressure is maximal because of the presence of large perforating veins. It is associated with characteristic skin changes of lipodermatosclerosis in the lower extremities: Capillary proliferation, fat necrosis, and fibrosis of skin and subcutaneous tissues. The unabated venous hypertension may result in these dermal changes with hyperpigmentation, subcutaneous tissue fibrosis (lipodermatosclerosis), and eventual ulceration. Venous ulcers are generally irregular and shallow, and often occur over bony prominences. The recurrence of an ulcer in the same area is highly suggestive of venous ulcer. The prevalence of venous ulcers is about 1 to $2 \%$ and, about $14 \%$ patients have diabetes. Venous ulcers are often recurrent, and open ulcers can persist from weeks to many years. Severe complications include cellulitis, osteomyelitis, and malignant change..$^{10,11}$

\section{DIABETIC BULLAE}

Diabetic bullae, or bullous diabeticorum, are generally seen in adults with long-standing diabetes, and may mimic diabetic foot with cellulitis. It is more commonly seen in those with peripheral neuropathy. These are usually confined to hands and feet, and are seen in about $0.5 \%$ of patients with diabetes. Typically, they arise spontaneously with a sudden blister or bullae formation and are primarily on the dorsa and the sides of lower legs and feet. Occasionally, they are seen on forearms and hands. The lesions contain clear sterile fluid on a noninflammatory base. They are painless and resolve spontaneously by themselves in 2 to 4 weeks' time. The treatment is aimed at local wound care with bullae evacuation while keeping the roof of the lesion intact. It may be necessary to perform a biopsy to rule out other disorders, such as bullous pemphigous and squamous cell carcinoma, among others. Even though the disease course is selfremitting, it is still possible to prevent secondary infection by use of good local wound care and antibiotics when necessary. ${ }^{12,13}$ 


\section{NECROBIOSIS LIPOIDICA DIABETICORUM}

Necrobiosis lipoidica is a fairly uncommon condition, seen in about 0.3 to $1.6 \%$ patients with diabetes. It typically occurs in young and middle-aged patients, and is more common in women. Most commonly the lesions occur on the pretibial skin as irregular, painless ovoid plaques with a yellow atrophic center and a red to purple periphery. Lesions typically have prominent, crossing telangiectasias and ulcerate (spontaneously or from trauma) in a third of the documented cases. The lesions range in size from a few millimeters to several centimeters. Typically, the lesions are bilateral in nature (Fig. 1E). Histologically, one will see epidermal atrophy and degenerative changes in collagen with granulomatous changes in the reticular dermis and fatty deposition in the papillary dermis. There is no relation to glycemic control, and glycemic control has no effect on the course of necrobiosis lipoidica.

Necrobiosis lipoidica is a benign condition, and the exact cause is currently unknown. Likely causes are localized trauma, microangiopathy, immunoglobulins and fibrin deposition, and metabolic changes.

Treatment is conservative in nature, mainly using topical or intralesional steroids to calm acute flares. However, steroid use in chronic lesions may exacerbate the already present cutaneous atrophy. Ulcerations may become prominent and one would accordingly implement

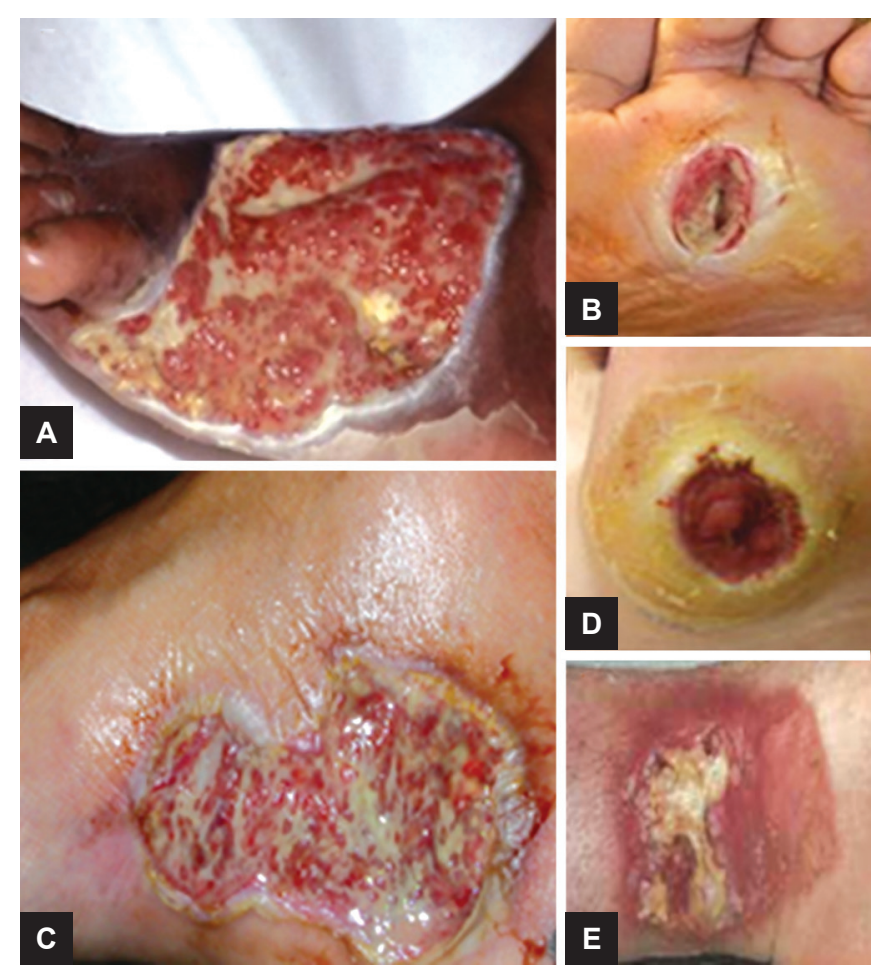

Figs 1A to E: (A) Diabetic foot ulcer; (B) pyoderma gangrenosum; (C) diabetic foot ulcer; (D) squamous cell carcinoma in a chronic ulcer; and (E) necrobiosis lipoidica diabeticorum local wound care. Stockings can be used to help with stasis changes and protection from trauma. ${ }^{12,14,15}$

\section{THROMBOANGIITIS OBLITERANS (BUERGER DISEASE)}

Thromboangiitis obliterans, also known as Buerger disease, is an inflammatory vasculopathy. It is characterized by an inflammatory endarteritis leading to a prothrombotic state and subsequent vaso-occlusive phenomena. It is strongly associated with smoking and tobacco use. It characteristically affects small and medium-sized arteries as well as veins of the upper and lower extremities. Most commonly, the patients present with moderate-to-severe claudication, which can quickly progress to critical limb ischemia with rest pain or tissue loss. Features of acute limb ischemia, such as pain, paresthesia, pallor, mottling, and absence of pulses are common. Most patients with TAO (70-80\%) present with distal ischemic rest pain or ischemic ulcerations on the toes, feet, or fingers. Patients may also often describe experiencing the Raynaud phenomenon. Patients who delay seeking medical attention may present with foot infections and, occasionally, with florid sepsis. Patients with TAO can develop painful ulcerations or frank gangrene of the digits. The hands and feet of patients with the disease are usually cool and mildly edematous. Hence, it can be easily confused with a diabetic foot infection. There is no cure for TAO. The goal of treatment is to control symptoms and prevent the disease from getting worse. ${ }^{16,17}$

\section{SUPERFICIAL THROMBOPHLEBITIS}

Superficial thrombophlebitis is a common inflammatorythrombotic disorder and it occurs in almost half of patients with TAO. Superficial thrombophlebitis can occur spontaneously, especially in the lower extremities in the great saphenous vein, or as a complication of medical or surgical interventions. More than $80 \%$ of patients present with involvement of three or four limbs. The condition usually presents as redness and tenderness along the course of the vein, usually accompanied by swelling. It is accompanied by paresthesia (numbness, tingling, burning, hypoesthesia) of the feet and hands. Impaired distal pulses in the presence of normal proximal pulses are found in patients with severe disease. Normal veins are distended visibly at the foot, the ankle, and, occasionally, the popliteal fossa, but not in the rest of the leg. Normal veins may be visible as a blue, subdermal, reticular pattern, but dilated superficial leg veins above the ankle usually are evidence of venous pathology. Superficial thrombophlebitis can be easily confused with cellulitis. $^{18}$ 


\section{GRANULOMA ANNULARE}

Granuloma annulare is a benign inflammatory dermatosis, which is characterized clinically by dermal papules and annular plaques. It presents as erythematous-to-fleshcolored papules, which coalesce to form an oval or ring lesion. It is usually asymptomatic but can cause pruritis or burning sensation. It is relatively common in all age groups, but it is rare in infancy. The precise cause and pathogenesis of granuloma annulare is currently unknown. Histological examination reveals foci of degenerative collagen associated with palisaded granulomatous inflammation. The association between granuloma annulare and diabetes is controversial; seen in about 9 to $21 \%$ cases in various studies. The skin lesions can also precede diabetes. Treatment includes topical or intra-lesional steroids. ${ }^{19,20}$

\section{ERYTHEMA NODOSUM}

Erythema nodosum is usually a self-limiting condition, presenting as tender red nodules or lumps on the skin. It occurs due to inflammation of fat cells under the skin, probably resulting from delayed hypersensitivity due to a variety of antigens. It may be idiopathic in almost half of the cases, or may be associated with infections (Streptococcus, Mycoplasma, TB), autoimmune diseases (inflammatory bowel diseases (IBD), Sarcoidosis), or medications (Penicillins). Treatment involves bed rest, leg elevation, use of compression, wet dressings, and nonsteroidal anti-inflammatory agents. ${ }^{21}$

\section{SUMMARY}

- Every ulcer in a diabetic need not be a diabetic foot ulcer

- Chronic ulcers/nonhealing ulcers should always be subject to histopathological evaluation

- A low threshold should be entertained for differentials.

\section{CONTRIBUTIONS}

RD and MAS prepared the manuscript. SKW provided valuable inputs and revision of the manuscript.

\section{REFERENCES}

1. Abbott CA, Carrington AL, Ashe H, Bath S, Every LC, Griffiths J, Hann AW, Hussein A, Jackson N, Johnson KE, et al. The North-West Diabetes Foot Care Study: incidence of, and risk factors for, new diabetic foot ulceration in a communitybased patient cohort. Diabetic Med 2002 May;19(5):377-384.
2. DeFilippis EM, Feldman SR, Huang WW. The genetics of pyoderma gangrenosum and implications for treatment: a systematic review. Br J Dermatol 2015 Jun;172(6):1487-1489.

3. Callen JP. Pyoderma gangrenosum. Lancet 1998 Feb 21;351(9102):581-585.

4. Callen JP, Jackson JM. Pyoderma gangrenosum: an update. Rheum Dis Clin North Am 2007 Nov;33(4):787-802.

5. Hill BB, Sloan DA, Lee EY, McGrath PC, Kenady DE. Marjolin's ulcer of the foot caused by nonburn trauma. South Med J 1996 Jul;89(7):707-710.

6. Königová R, Rychterová V. Marjolin's ulcer. Acta Chir Plast 2000;42(3):91-94.

7. Baskara A, Sikka L, Khan F, Sapanara N. Development of a Marjolin's ulcer within 9 months in a plantar pressure ulcer. Eur J Dermatol 2010 Mar-Apr;20(2):225.

8. Bauer T, David T, Rimareix F. Marjolin's ulcer in chronic osteomyelitis: seven cases and a review of the literature. Rev Chir Orthop Reparatrice Appar Mot 2007 Feb;93(1):63-71.

9. Agale SV, Kulkarni DR, Valand AG, Zode RR, Grover S. Marjolin's ulcer - a diagnostic dilemma. J Assoc Physicians India 2009 Aug;57:593-594.

10. O'Meara S, Al-Kurdi D, Ologun Y, Ovington LG. Antibiotics and antiseptics for venous leg ulcers. Cochrane Database Syst Rev 2010 Jan 20;(1):CD003557.

11. Abbade LP, Lastória S. Venous ulcer: epidemiology, physiopathology, diagnosis and treatment. Int J Dermatol 2005 Jun;44(6):449-456.

12. Ferringer T, Miller F 3rd. Cutaneous manifestations of diabetes mellitus. Dermatol Clin 2002 Jul;20(3):483-492.

13. Tabor CA, Parlette EC. Cutaneous manifestations of diabetes. Postgrad Med 2006 Sep-Oct;119(3):38-44.

14. Lowitt MH, Dover JS. Necrobiosis lipoidica. J Am Acad Dermatol 1991 Nov;25(5 Pt 1):735-748.

15. O'Toole EA, Kennedy U, Nolan JJ, Young MM, Roger S, Barnes L. Necrobiosis lipoidica: only a minority of patients have diabetes mellitus. Br J Dermatol 1999 Feb;140(2):283-286.

16. Espinoza LR. Buerger's disease: thromboangiitis obliterans 100 years after the initial description. Am J Med Sci 2009 Apr;337(4):285-286.

17. Dargon PT, Landry GJ. Buerger's disease. Ann Vasc Surg 2012 Aug;26(6):871-880.

18. Schonauer V, Kyrle PA, Weltermann A, Minar E, Bialonczyk C, HirschlM, Quehenberger P, Schneider B, Partsch H, EichingerS. Superficial thrombophlebitis and risk for recurrent venous thromboembolism. J Vasc Surg 2003 Apr;37(4):834-838.

19. Struder E, Calza A, Saurat J. Precipitating factors and associated disorders in 84 patients with granuloma annulare: a retrospective study. Dermatology 1996;193(4):364-368.

20. Dabski K, Winkelmann R. Generalized granuloma annulare: clinical and laboratory findings in 100 patients. J Am Acad Dermatol 1989 Jan;20(1):30-47.

21. Requena L, Yus ES. Erythema nodosum. Dermatol Clin 2008 Oct;26(4):425-438. 